\title{
Emprendimientos de memoria y trabajos de archivo. El archivo del Centro de Derechos Humanos Fray Bartolomé de las Casas (Frayba)
}

\section{Memory entrepreneurs and archival practices. The archive of the Fray Bartolomé de las Casas Human Rights Center (Frayba)}

\author{
Antonio J. HeRnÁndeZ* \\ Guillermo Pereyra** \\ doi.org/10.29043/liminar.v20i1.876
}

Resumen: El objetivo general de este artículo es mostrar las actividades que realiza el Centro de Derechos Humanos Fray Bartolomé de las Casas (Frayba), una organización civil sin fines de lucro ubicada en San Cristóbal de Las Casas, Chiapas, México, en torno a la memoria y el archivo mediante entrevistas y análisis documental. En particular se busca, por un lado, comprender y discutir cómo documentan y analizan (no solo judicialmente) los casos de violaciones de los derechos humanos que atienden a partir de los testimonios de las víctimas y, por el otro, cómo construyen y preservan su archivo. En nuestra opinión, los activistas de derechos humanos del Frayba son "emprendedores de memoria" (E. Jelin) en un contexto de violencia. Un rasgo característico de sus actividades de registro, recopilación y archivo es el activismo político, a partir del cual llevan a cabo un proyecto político de construcción y reconstrucción del pasado.

Palabras clave: Centro de Derechos Humanos Fray Bartolomé de las Casas, memoria histórica, prácticas de archivo, activismo político.

Abstract: The general objective of this article is to analyze the activities of the Fray Bartolomé de Las Casas Human Rights Center (Frayba), a non-profit civil organization located in San Cristóbal de las Casas, Chiapas, Mexico, in terms of memory and archival practices. Information was gathered through interviews and documentary analysis. In particular, we endeavor to understand and discuss how Frayba workers document and analyze human rights violations (not just judicially), based on victims' testimonies and on how they classify and curate their archive. In our opinion, Frayba's human rights activists are "memory entrepreneurs" (E. Jelin) working in a violent context. A distinctive feature of their registry, collection, and archival practices is political activism, which underlies their political project that builds, and reconstructs, a troubled past.

Key words: Fray Bartolomé de las Casas Human Rights Center, historical memory, archive practices, political activism.

Recibido: 11 de agosto de 2020 Aprobación: 14 de junio de 2021 Publicación: 12 de agosto de 2021
* Escuela Nacional de Restauración, Conservación y Museografía Manuel del Castillo Negrete del Instituto Nacional de Antropología e Historia (ENCRyM-INAH), México. antonio_hernandez_c@encrym.edu.mx (iD) 0000-0003-3848-3063

** Escuela Nacional de Restauración, Conservación y Museografía Manuel del Castillo Negrete del Instituto Nacional de Antropología e Historia (ENCRyM-INAH), México. guillermo_pereyra_@encrym.edu.mx (iD) 0000-0003-3152-9620 


\section{Introducción}

$\mathrm{E}$ Centro de Derechos Humanos Fray Bartolomé de las Casas (Frayba), organización civil sin fines de lucro, está ubicado en San Cristóbal de Las Casas, Chiapas, México. Fue fundado en el año 1989 por iniciativa de Samuel Ruiz García, obispo de la diócesis de San Cristóbal. ${ }^{1}$ Desde entonces se ha dedicado a la defensa y promoción de los derechos humanos, en particular los de los pueblos indígenas de Chiapas. Aunque comenzó siendo un órgano diocesano y en aquellos años no se utilizaba el lenguaje de los derechos humanos, sino el de la "defensa del pobre", luego se convirtió en una asociación civil, autónoma de la Iglesia y plural en términos religiosos, esto es, incluye a católicos y no católicos, sin restringir su visión a la eclesial (informante 3). ${ }^{2}$ Como otras agrupaciones populares vinculadas al trabajo eclesial de base, el Frayba se constituyó como una organización no gubernamental que no tenía un perfil elitista.

La fundación del Frayba obedeció a dos procesos históricos que se desarrollaron a partir de la década de 1980. El primero de ellos fue la institucionalización de organizaciones no gubernamentales pioneras en México en la defensa de los derechos humanos, que buscaron espacios autónomos que escaparan del control represivo que ejercía el Partido de la Revolución Institucional (PRI) (López, 2015, p. 99). Este centro pertenece, junto al Centro de Derechos Humanos Miguel Agustín Pro Juárez (Centro ProDH), la Comisión Mexicana de Defensa y Promoción de los Derechos Humanos (CMDPDH), el Centro de Derechos Humanos Fray Francisco de Vitoria (CDH Vitoria) y la Asociación de Cristianos contra la Tortura (ACAT), a los orígenes de las luchas por la democracia en México, que se extendieron entre 1980 y 2000. El Frayba puede ser caracterizado como una organización de activismo político histórico, con una agenda definida por la exigencia de transformaciones sociales y políticas profundas y una crítica permanente al accionar de los gobiernos a nivel federal y estatal (López, 2015, p. 104; 2017).

A finales de los años ochenta, diversas organizaciones no gubernamentales decidieron incorporar la defensa legal de casos paradigmáticos de violación de derechos humanos. Los litigios jurídicos que iniciaron la CMDPDH, el Centro ProDH y el Frayba les confirieron un alto grado de experticia, y esta profesionalización les permitió presionar al gobierno federal y participar en distintas acciones colectivas (López e Hincapié, 2016, p. 29). La combinación de experticia jurídica, acompañamiento de la movilización popular y militancia sostenida explica que el Frayba se haya consolidado como un receptor de demandas de sectores menos favorecidos de Chiapas, en un contexto de crisis de los derechos humanos que se prolonga hasta la actualidad.

El segundo factor histórico es de carácter local. Los años setenta y ochenta forman parte de un periodo de violación sistemática de los derechos humanos en Chiapas. Las detenciones arbitrarias, las

\footnotetext{
${ }^{1}$ El orden de los autores es exclusivamente alfabético; ambos aportaron el mismo trabajo para la elaboración de este artículo. Agradecemos, en primer lugar, a las personas que generosamente nos permitieron conocer sus historias, las cuales constituyen la base principal del texto y sobre todo la razón de ser de esta investigación. En segundo lugar, agradecemos a los dictaminadores anónimos cuyos comentarios contribuyeron significativamente a ampliar y precisar nuestros argumentos.

${ }^{2}$ Referimos como "informantes" en este trabajo, numerados consecutivamente del 1 al 4 , a las personas que accedieron a atender nuestras entrevistas. Las entrevistas de 2016 que citamos como informantes 1 a 4 se realizaron en San Cristóbal de Las Casas en las siguientes fechas: 15 de noviembre (informante 1), 18 de septiembre (informantes 2 y 3 ) y 22 de noviembre (informante 4).
} 
ejecuciones extrajudiciales, las desapariciones forzadas y las torturas, así como las políticas racistas del gobierno estatal y la violencia de la clase terrateniente, fueron determinantes para que Samuel Ruiz y sus seguidores fundaran una institución de derechos humanos que atendiera este grave problema (Jiménez, 2000, pp. 52-53). Fue un momento político crucial en Chiapas, pues la respuesta a la represión estatal fue una creciente organización popular que se cristalizó en el Congreso Indígena de 1974. Muchos describen este congreso como un acontecimiento fundamental en la politización de los pueblos indígenas. Ruiz subraya en la carta pastoral de 1993 que en ese evento mil comunidades de las cuatro zonas lingüísticas de Chiapas (chol, tseltal, tsotsil y tojolabal) "hicieron pública su voz en tantos años de silencio" y presentaron "datos lacerantes e innegables", citando fechas, lugares, personas y hechos, referidos al abuso en el comercio, la explotación laboral, el despojo de las tierras, la destrucción de la cultura y los asesinatos impunes (Ruiz, 1993, p. 26). Samuel Ruiz forjó junto con otros activistas de derechos humanos la tradición de hacer visible la violencia en Chiapas aportando información sobre ella en la esfera pública. Heredero del Congreso Indígena y del trabajo diocesano, el Frayba pudo imprimir un nuevo carácter a la defensa de los derechos humanos a través de la denuncia pública, la documentación de casos y la aportación de datos y pruebas.

Especial, aunque no exclusivamente en el marco del conflicto armado interno iniciado con el alzamiento del Ejército Zapatista de Liberación Nacional (EZLN) en enero de 1994, el Frayba se ha dedicado a atender, denunciar públicamente, documentar y litigar violaciones de derechos humanos, en particular casos de ejecuciones, tortura, detenciones arbitrarias, desapariciones y desplazamiento forzado. Cuenta también con una intensa participación en el trabajo internacional de defensa de los derechos humanos. En 1994 formó parte del equipo internacional que viajó a Washington y Ginebra para denunciar la situación de México tras el alzamiento zapatista (Maza, 2012, p. 28). En los últimos años, perfeccionó su activismo jurídico transnacional y logró tener una presencia importante en la Comisión Interamericana

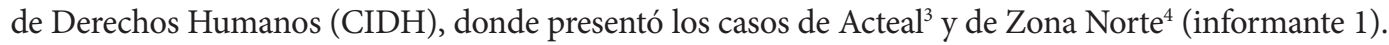
Junto con la organización no gubernamental Tlachinollan, logró que la CIDH dedicara sesiones especiales a derechos de los pueblos indígenas, libertad de expresión, derechos de los migrantes en tránsito y protección a los activistas de derechos humanos. Liderar estas sesiones le permitió al Frayba posicionar su agenda regional y evidenciar los abusos que sufren los pueblos indígenas debido a su oposición al desarrollo de megaproyectos (López e Hincapié, 2017, p. 24).

El Frayba se organiza internamente en áreas de trabajo: Dirección; Trabajo Regional; Sistematización e Incidencia Social; Planeación, Monitoreo, Evaluación y Procuración de Fondos; Administración y Contabilidad; y el Equipo de Conducción (compuesto por la Dirección y las coordinaciones de áreas). Por lo menos desde 1993, entre sus trabajos se encuentra la difusión de informes sobre la situación de los derechos humanos en la entidad. En su página web se encuentran más de 50 informes (el primero

\footnotetext{
${ }^{3}$ Masacre que tuvo lugar en la comunidad de Acteal, municipio de Chenalhó, Chiapas, el 22 de diciembre de 1997. Fueron asesinados 45 indígenas y 26 de ellos fueron heridos por el grupo paramilitar Máscaras Rojas, que actuó con la anuencia del Ejército. Las víctimas incluyen a adultos y niños, hombres y mujeres, algunas de ellas embarazadas. El Frayba realizó varios informes sobre este crimen de lesa humanidad (CDHFBC, 1998a; 1998b; 2004a; 2007a; 2008a; 2009b).

${ }^{4}$ El Frayba publicó dos informes sobre las desapariciones y ejecuciones efectuadas por el grupo paramilitar Paz y Justicia en la zona Norte de Chiapas (CDHFBC, 1995; 2004b). Entre 1995 y 2001 registró 122 casos de violaciones a los derechos humanos en esa región y seleccionó ocho de ellos para denunciar la responsabilidad del Estado mexicano ante la CIDH (CDHFBH, 2009a, p. 77).
} 
publicado en 1993) que se pueden clasificar en dos grupos. El primer grupo está integrado por sus balances anuales, que documentan las violaciones a los derechos humanos cometidas cada año en Chiapas. Publicados intermitentemente desde 1999, en los últimos años han circulado reportes especiales, comunicados, pronunciamientos y boletines. El segundo grupo de informes son los reportes especiales, que versan sobre alguna temática particular que merece ser atendida por su importancia o gravedad. ${ }^{5}$ Su periodicidad es constante desde 1993 hasta el presente. Tales informes, disponibles en formato electrónico, constituyen un archivo digital de sus actividades y sobre todo de la situación política regional desde su punto de vista. Aunque el Frayba no es un archivo o un centro de documentación, entre sus principales objetivos aparece explícitamente la recuperación de la "memoria histórica", y la elaboración y difusión de los informes es concebida como una tarea de memoria.

Su larga trayectoria y sus características como asociación nos impulsaron a acercarnos al Frayba para conocer qué actividades realizaban en torno a la memoria y cuáles eran sus principales logros y desafíos. Nos interesaba especialmente, por un lado, cómo documentaban y analizaban (no solo judicialmente) los casos que atendían a partir de los testimonios de las víctimas; por otro, cómo construían y preservaban su archivo. Siguiendo a Elizabeth Jelin (2002), nos preguntamos por los marcos interpretativos de carácter social que daban sentido a aquellas prácticas de defensa de los derechos humanos que estaban más directamente vinculadas con la memoria de las víctimas y los procesos de recopilación, registro y archivación de huellas de las violaciones a los derechos humanos en la región. Como escribe Jelin, adaptando el concepto de Maurice Halbwachs, la memoria no es solo individual, tiene una dimensión colectiva. Se trata de:

[...] memorias compartidas, superpuestas, producto de interacciones múltiples, encuadradas en marcos sociales y en relaciones de poder. Lo colectivo de las memorias es el entretejido de tradiciones y memorias individuales, en diálogo con otros, en estado de flujo constante, con alguna organización social -algunas voces son más potentes que otras porque cuentan con mayor acceso a recursos y escenarios-y con alguna estructura, dada por códigos culturales compartidos (Jelin, 2002, p. 22).

Para explorar y comprender estas cuestiones, entre el 13 y el 23 de noviembre de 2016 visitamos las instalaciones del Frayba en San Cristóbal de Las Casas, así como el Archivo Diocesano (que resguarda, entre otros, el Fondo Samuel Ruiz), una parroquia y el Museo Jtatik Samuel, los tres situados en la misma ciudad. Visitamos nuevamente el Frayba y el museo entre el 11 y el 14 de septiembre de 2018. Realizamos seis entrevistas semiestructuradas a actores directa o indirectamente involucrados con el Frayba en diversos periodos de su trayectoria (cuatro grabadas y transcritas, una transcrita al momento

\footnotetext{
${ }^{5}$ Se documentaron los siguientes casos y temas: violencia y paramilitarización en la zona Norte (1995, 1998 y 2004); detención y expulsión de sacerdotes de la diócesis de San Cristóbal de Las Casas (1995); violencia en Chenalhó (1997); masacre de Acteal (1998, 2004, 2007, 2008 y 2009); ataques a la población en El Bosque (1999); expulsiones y violaciones a los derechos humanos en San Juan Chamula (2001, 2002); tortura (2001, 2002, 2012 y 2014); desplazamientos internos (2002); detenciones arbitrarias (2002); desalojo forzado y desplazamiento en Buen Samaritano y San Manuel, Montes Azules (2007); masacre de Chinkultic (2008); agresiones y tortura en Mitzitón (2010); agresiones, desalojo forzoso y tortura contra manifestantes en Las Rosas (2010); ataque armado al pueblo zapatista de Bolom Ajam (2010); creación y administración de conflictos por parte del Estado para el control territorial (2011); violaciones a los derechos humanos en las cárceles (2011); violencia generalizada en Venustiano Carranza (2013); debate sobre los derechos humanos (2014); luchas por la defensa de los derechos humanos y resistencia popular (2010, 2016, 2018); ejecuciones extrajudiciales (s. f.), y grupos paramilitares (s. f.).
} 
sin aparato de grabación y una sin grabación ni transcripción). Por razones de confidencialidad, mantenemos el anonimato de los informantes. Asimismo, hicimos una revisión sistemática de los informes anuales y especiales del Frayba a lo largo de los años. Estas fuentes primarias sostienen nuestra argumentación.

\section{Nexos entre memoria, historia y archivo}

Enzo Traverso (2007) advierte que la reciente inquietud por la memoria, surgida a raíz de las catástrofes sociales del siglo XX, corre el riesgo de omitir la diferencia crucial entre memoria e historia.

Historia y memoria, en términos generales, coinciden en ser elaboraciones del pasado, pero sus modos de elaboración tienen algunas diferencias. Al menos desde un punto de vista típico-ideal, el historiador escribe el pasado según las reglas de su oficio: contextualización, cronología, aportación de pruebas, comparación y generalización, entre otras. La historiografía sigue, en este aspecto, procedimientos similares a los de la institución jurídica: la pesquisa, la identificación de los testimonios, el registro, la comparecencia de las partes, la decisión y la ejecución (Déotte, 1998, p. 24). El testigo sigue otras reglas. Extrae su relato - puede ser escrito, pero es a menudo oral, mientras la historia es siempre escritura - de su propia experiencia, de la experiencia vivida. Su vinculación con los acontecimientos parte de las huellas que aquellos dejaron en él. Sus fuentes, por decirlo así, son esas huellas que el pasado ha ido depositando en su vida en forma de recuerdos; por eso su verdad es evocativa, no probatoria, o, como decían los historiadores antiguos, vívida (Ginzburg, 2010, pp. 19 y ss). En este sentido, el testimonio es singular, transita de un evento concreto a otro, de un nombre propio al otro; la cronología de los acontecimientos puede ser, para él, secundaria, cuando no irrelevante (por ejemplo, en la temporalidad acrónica del trauma). Los testigos no aportan pruebas, ellos mismos son las pruebas; las portan, por tanto, no las necesitan.

El testigo, en una palabra, rememora. Con todas las limitaciones del oficio, el historiador, por el contrario, más que rememorar una experiencia vivida, intenta comprender el pasado a partir de tales experiencias, incluso cuando él mismo, en casos en los que hay una proximidad temporal y un involucramiento personal, también ha sido testigo de aquello que estudia. En este sentido, no ocupa un ámbito radicalmente distinto al de la memoria, pero sí uno no del todo homologable con ella. La historia aspira a responder las cuestiones que el relato del testigo suscita y, en este sentido, su elaboración pertenece a la memoria y es una forma de rememoración. No obstante, sin abandonarla, el historiador está obligado a introducir un distanciamiento reflexivo respecto a la memoria, por lo que, de alguna manera, está comprometido con cierta "objetivación" de los testimonios, incluso - o sobre todo- cuando siente empatía por quienes experimentaron el horror. La escritura de la historia responde a una retórica, pero esta retórica es la de la cronología y la prueba, la de la verdad como verificación empírica y no evocación vívida, lo que lo obliga, para reconstruir el pasado, a la crítica de fuentes, al montaje analítico de unos testimonios con otros y a la comparación de todos ellos con otras huellas resguardadas en los archivos. $\mathrm{Su}$ resultado es un relato con nomenclatura y pretensiones probatorias. En contextos de violencia, la comprensión histórica se relaciona mediata y no inmediatamente con la catástrofe; el relato que producen los historiadores se aproxima a los acontecimientos del pasado a través del relato de los testigos, pero sin convertirse en su espejo. Los acontecimientos se sitúan, ante el historiador, en un proceso que los incluye y, al mismo tiempo, los desborda. El testigo lo es siempre del acontecimiento y no requiere otro archivo, 
por decirlo de alguna manera, que la reunión de sus propios recuerdos, el archivo compuesto por huellas mnémicas. En efecto, así como hay huellas materiales - lugares, objetos, papeles_, también hay huellas corporales y psíquicas que tienen la forma de recuerdos (Jelin, 2002, p. 30).

La advertencia de Traverso (2007) no consiste en indicar que exista un abismo irreductible entre la historia y la memoria, sino en subrayar que el paso de la nominación a la anonimia, del acontecimiento al proceso, muestra que no siempre son idénticas. Es decir, Traverso enfatiza una doble inaccesibilidad: la del recuerdo para el historiador y la de la comprensión para el testigo. La doble inaccesibilidad entre la rememoración testimonial y la rememoración historiográfica. La historia y la memoria en modo alguno constituyen mundos separados, se yuxtaponen de distintas maneras, pero son, en algún punto crucial, distintas. Nuestra reflexión sobre la experiencia del Frayba quiso situarse precisamente en la interpenetración, no en la antítesis, entre historia y memoria. Como ha señalado Dominick LaCapra, la historia y la memoria no son ni idénticas ni opuestas, sino suplementarias: "tienen una relación suplementaria que es la base para una interacción mutuamente cuestionadora o para un intercambio dialéctico que nunca alcanza la totalización o una clausura absoluta. La memoria es a la vez más y menos que la historia y viceversa" (LaCapra, 2008, p. 33).

Quien escribe la historia de la violencia puede presuponer que los acontecimientos quedan registrados en los archivos, pero, entre otras preguntas que problematizan la relación acontecimiento-archivo, siempre cabe preguntarse qué ocurre con la violencia que no se inscribe en los archivos y, en general, en las instituciones de la memoria nacional. Para crímenes como la desaparición forzada, los asesinatos masivos o la tortura suele no haber registros ni archivos (Déotte, 1998, p. 24), o bien, si los hay, los proyectos de memoria que impulsan la construcción, el resguardo y la apertura de los archivos de derechos humanos entran en tensión con el derecho a la privacidad de las víctimas o razones de seguridad estatal (Hartog, 2007, p. 131). Los testimonios de quienes padecen violaciones suelen quedar suspendidos en un lugar inestable entre lo no registrado, el registro disponible, los obstáculos para acceder a él y la recepción colectiva, aunque, en medio de estas dificultades, los acontecimientos irresueltos a menudo regresan a la memoria - una memoria que puede ser llamada benjaminianamente mesiánica- de los testigos, y también de los activistas y otros actores comprometidos con ella.

El testigo y el historiador pueden colaborar o disputar en el proceso de construcción de la historia/ memoria de una sociedad o grupo que sufrió la violación de sus derechos. También los activistas y otros actores sociales, como políticos profesionales, intelectuales, abogados o funcionarios, pueden participar en el proceso. En nuestro caso, el trabajo de las agrupaciones de derechos humanos con raigambre histórica puede combinar la recopilación, el registro y la archivación de huellas de las experiencias de violencia con la crítica política e intelectual que revela el pasado obturado de una sociedad desde el punto de vista de las agrupaciones. La categoría de "emprendedores de la memoria", propuesta por Jelin, permite captar rasgos fundamentales de este activismo motivado por la causa de la memoria: se trata de actores sociales que, a menudo en tensión o confrontación con otros actores que tienen otras versiones y las politizan, se movilizan colectivamente para alcanzar el reconocimiento público de su versión de un pasado conflictivo (Jelin, 2002, p. 48). En la historia reciente de México y América Latina, algunos grupos de víctimas, familiares y activistas de derechos humanos se han convertido en emprendedores de la memoria. Desde sus marcos interpretativos y como parte de procesos de construcción de memorias colectivas, han elaborado y reelaborado el pasado conflictivo en función de proyectos de carácter político, con trayectorias singulares y resultados disímiles. En situaciones históricas en las que ha solido 
imperar la impunidad y una voluntad de olvido proveniente de las instituciones públicas, o en las que el sentido oficial del pasado no se corresponde con el pasado vivido e interpretado por algunos grupos, las luchas de los emprendedores de la memoria han tenido con frecuencia al Estado como adversario.

En el contexto de tales proyectos de memoria se pueden situar las prácticas de documentación y archivación que realizan algunas organizaciones de derechos humanos. Estas prácticas, cuando tienen lugar, hacen posible escribir una historia que no está escrita o permanece en disputa, en circunstancias en las que las huellas de la catástrofe social no siempre encuentran - como señala Jean-Louis Déotte (1998) - una "superficie de inscripción" en las instituciones de la historia oficial. En este sentido, es preciso tener en cuenta la relación, pero también la diferencia, entre las huellas y sus usos y evocaciones sociales, entre los archivos y las memorias. Como señala la propia Jelin:

Pueden existir restos y rastros almacenados, saberes reconocibles, guardados pasivamente, información archivada en la mente de las personas, en registros, en archivos públicos y privados, en formatos electrónicos y en bibliotecas [...]. Pero éstos son reservorios pasivos, que deben distinguirse del uso, del trabajo, de la actividad humana en relación con ellos [...]. La existencia de archivos y centros de documentación, y aun el conocimiento y la información sobre el pasado, sus huellas en distintos tipos de soportes reconocidos, no garantizan su evocación. En la medida en que son activadas por el sujeto, en que son motorizadas en acciones orientadas a dar sentido al pasado, interpretándolo y trayéndolo al escenario del drama presente, esas evocaciones cobran centralidad en el proceso de interacción social (Jelin, 2002, pp. 22-23).

Es preciso, por tanto, reconocer el proceso que experimentan las huellas desde su producción hasta sus usos. Recopilar, registrar y archivar son prácticas sociales que mantienen la posibilidad de su evocación, pero no conducen inmediatamente a tal evocación ni anticipan el contenido de lo evocado. Documentos y archivos, al igual que museos, bibliotecas o lugares, son "vehículos de la memoria" (Jelin, 2002, p. 37). Dicho de otra manera, sin archivos el trabajo de la memoria se hace difícil y en ocasiones imposible; en cualquier caso, los archivos la vehiculan, pero no son en sí mismos la memoria.

\section{Documentación y análisis. Los informes del Frayba como archivo}

Los informes del Frayba son una forma de escritura de la historia/memoria, constituyen un emblema de su activismo en relación con la memoria y, con el paso del tiempo, se han convertido en un tipo de archivo. Como emprendedores de memoria, los activistas documentan y analizan los relatos de los testigos de la violencia, pero no con un interés meramente historiográfico, sino para colaborar en que sus relatos irrumpan en el espacio público y, finalmente, denunciar lo sucedido, reclamando verdad y justicia. A partir de la denuncia jurídico-política, la verdad y la justicia constituyen el término ad quem de sus actividades, son aquello que responde al para qué de la documentación y, en general, del archivo.

En este sentido, cabe preguntar: ¿ cómo fueron documentados y analizados los acontecimientos de violencia a lo largo de tiempo? ¿Cómo se expresó el proyecto político del Frayba en los informes, en cuanto modos de escritura del pasado?

El Frayba, a la par que documenta, comprende y analiza la realidad social de la violencia en Chiapas, definiéndola como un "conflicto armado interno no resuelto". Desde el levantamiento zapatista de 
1994, las violaciones a los derechos humanos no han dejado de sucederse en el estado. Se ha señalado que la estrategia contrainsurgente trasciende el control territorial militar, pues se vale de todo tipo de recursos (políticos, económicos, sociales, psicológicos y mediáticos) para presentar el conflicto como una confrontación entre comunidades indígenas que responde a motivos religiosos, étnicos o personales (Leyva y Köhler, 2016, pp. 319-320). El Frayba ha tenido en ese contexto una participación fundamental en la documentación de las ejecuciones, las desapariciones forzadas, las torturas y las detenciones arbitrarias cometidas por miembros del ejército, autoridades del gobierno de Chiapas y grupos paramilitares. Así lo constató en 2000 Marta Patricia Jiménez Ramírez, exdirectora del centro: "Hemos documentado innumerables situaciones de violaciones, nuevos y diversos acontecimientos marcan importantes tendencias en el desarrollo del conflicto en que vive el estado de Chiapas desde hace seis años" (Jiménez, 2000, p. 54). El Frayba documentó por primera vez la masacre de Acteal, más aún, fue la primera organización no gubernamental que llegó al lugar de los acontecimientos, registró los testimonios de los sobrevivientes y acompañó a estos judicial y psicológicamente. Por esta razón, sus informes sobre Acteal (CDHFBC, 1998a; 1998b; 2004a; 2007a; 2008a; 2009b) son textos con valor historiográfico, especialmente los dos publicados en 1998, que divulgaron el primer registro de los hechos y los primeros testimonios de las víctimas.

El informe es entendido por el Frayba como una denuncia ("grito de indignación y esperanza") y un "testimonio" (CDHFBC, 2001, p. 4). Se trata de un tipo de testimonio particular, pues el Frayba actúa como lo que se puede llamar un testigo de testigos: "Nos alimenta la esperanza de aportar y ser testigos de los procesos de las organizaciones y de las víctimas en su lucha por sus derechos" (CDHFBC, 2005, p. 4). Su actividad, en este sentido, se coloca en una relación de proximidad y, al mismo tiempo, de distanciamiento con las víctimas y los supervivientes de los distintos eventos de violencia en Chiapas. Dori Laub describió esta posición como aquella que caracteriza a "los testigos de los testigos del trauma" (1992, p. 84). Se trata de una cierta cercanía con la víctima que resulta de la escucha de su experiencia relatada en el testimonio, escucha que coparticipa y posibilita la emergencia y el despliegue del testimonio. Sin embargo, aunque el que escucha sea un testigo de la experiencia del testigo primario, la experiencia de quien vivió el trauma no es la de quien lo escucha. Este último preserva una perspectiva propia y separada.

El centro es testigo de las luchas de los oprimidos y también de algunos acontecimientos para los que no hay testigos, como lo es la tortura. En efecto, el único que puede atestiguar de un acto de tortura es la propia víctima: "Generalmente cuando se comete tortura no existen testigos. A ello se agrega que los perpetradores están vinculados institucionalmente con la autoridad investigadora, y ésta no realiza las pruebas pertinentes como los peritajes médicos y psicológicos que permitan confirmar o descartar la existencia de tortura" (CDHFBC, 2005, p. 18). En un contexto en el que el sistema de impunidad borra las huellas de la tortura y en el que nadie puede testimoniar por la víctima torturada, salvo ella misma, el Frayba ocupa un papel relevante en la inscripción de su demanda, primero, en los documentos resguardados en su propio archivo; después, en el espacio público. El testigo de testigos registra la voz de quien denuncia la tortura, pero también preserva y politiza la voz de los que ya no pueden emitirla: "Recordando, documentando y exigiendo el cabal esclarecimiento de los crímenes de lesa humanidad, mantenemos vivos, con respeto y justicia, a los que por su propia voz ya no pueden ser escuchados" (CDHFBC, 2009a, p. 83).

Además de preservar y politizar la voz de las víctimas, los informes expresan el trabajo de documentación y análisis del Frayba. En este caso, la escritura de la historia se parece más al trabajo del cronista 
que al del historiador stricto sensu. Walter Benjamin realiza una distinción entre ambas figuras que resulta útil para caracterizar la documentación y el análisis que realiza el centro. El cronista no es el historiador ${ }^{6}$ que explica objetivamente el encadenamiento necesario de los hechos, sino un narrador que apela a la exposición exegética y a la comprensión actualizada del pasado (Benjamin, 2001, p. 122). El cronista se interesa sobre todo en la letra pequeña de la historia, esto es, en los detalles que pasan inadvertidos en la historia oficial (Benjamin, 2008:306). Las crónicas del Frayba usualmente presentan los antecedentes del hecho, los derechos vulnerados, las características de las personas o del grupo afectado, los testimonios recabados, el papel de las autoridades, de la policía y de los militares, los efectos sociales y psicológicos de la violencia, y el análisis jurídico del caso. Polemizan contra las "versiones oficiales" y las "tergiversaciones" de los hechos promovidas por otros actores, frecuentemente por el Estado, tanto a nivel federal como estatal. Esta narrativa politizada se expresa en los debates que tienen lugar en el espacio público en torno a lo que se conoce y lo que se niega del conflicto armado en Chiapas. ${ }^{7}$ Los informes sobre Acteal, por ejemplo, relatan acciones y situaciones que son desestimadas en las llamadas versiones oficiales, como puede ser la política contrainsurgente del Estado mexicano, la paramilitarización en la zona Norte y Los Altos de Chiapas, la dilación de la justicia, "el cinismo del gobierno en Chiapas", las "cortinas de humo" y el impacto psicosocial de la masacre (CDHFBC, 1998a; 2004a; 2007a). Se polemiza con la intención de citar el pasado en el presente, como sucede en los informes que conmemoran este asesinato masivo. Se vuelve periódicamente al pasado para denunciar la impunidad que existe en torno al caso Acteal, en una palabra, para "no olvidar" (CDHFBC, 2004a; 2007a; 2007b; 2008a; 2009b).

La escritura polemista de la historia se combina en la mayoría de los informes con el análisis jurídico y el seguimiento de los casos. En la intervención de los profesionales del derecho se puede apreciar una distancia reflexiva frente a los sucesos. Esta retórica se superpone con la del cronista que rememora y polemiza, sin eliminarla. Cabe destacar que algunos reportes presentan exclusivamente información sobre procesos judiciales y administrativos (CDHFBC, 2007b; 2010a), o bien contienen testimonios de víctimas en los que los comentarios del Frayba pasan a segundo plano (CDHFBC, 1998b).

Ciertos hechos de violencia son caracterizados en los informes como acontecimientos fuera de serie, de los que no se tienen antecedentes debido a su magnitud y gravedad. En el reporte Acteal: entre el duelo y la lucha se documentaron en el periodo de seis meses posteriores a la masacre violaciones a los derechos humanos que "por su número no tienen punto de referencia en la historia reciente en el Estado” (CDHFBC, 1998a, pp. 14-15).

Destacar la singularidad de ciertos actos de violencia es uno de los recursos retóricos de los informes, el otro es inscribir los acontecimientos atestiguados en fenómenos históricos de larga duración que tienen efectos sociales persistentes. En este sentido, la documentación sirve para mostrar la existencia de patrones en las violaciones a los derechos humanos: "A partir de la documentación de denuncias que el Frayba realiza, así como del seguimiento de casos en litigio, se puede confirmar que en Chiapas

\footnotetext{
${ }^{6}$ El historiador materialista o el historiador que rememora, que se opone al historiador de cuño historicista y positivista, es próximo al cronista en tanto que "nada de lo sucedido se pierde para el historiador materialista" (Forster, 2012, p. 34). Como explicamos a continuación, el término cronista no debe interpretarse, de ninguna manera, según la tradición de los cronistas durante el proceso de conquista y colonización de América.

${ }^{7}$ Ver la polémica que mantuvo el Frayba con Héctor Aguilar Camín a propósito de los artículos que publicó en 2007 sobre la masacre de Acteal en la revista Nexos (CDHFBC, 2007a).
} 
la práctica de la tortura es real y constante" (CDHFBC, 2007c, p. 85). Por lo regular, el último informe publicado confirma situaciones graves anunciadas en informes anteriores. El balance anual del año 2007, por ejemplo, constata el clima de violencia detallado en el informe del año anterior. Ese clima estuvo determinado por el despojo de los territorios de los pueblos indígenas, la impunidad de los megaproyectos de inversionistas, la represión de la protesta social, la criminalización de las víctimas por parte de las autoridades, los procedimientos paramilitares y judiciales para permitir la apropiación de las tierras, la tortura como método de investigación de las fuerzas policiales, las privaciones arbitrarias de la libertad y el incremento de las agresiones contra activistas de derechos humanos (CDHFBC, 2007c, p. 124).

Aunque el Frayba realiza informes especiales sobre la situación de los derechos humanos en un momento particular del presente, la información que proporciona refleja un recuento histórico y analiza la relación entre la violencia de la actualidad y la del pasado. Es un recurso empleado en un gran número de reportes. Algunos se han escrito expresamente para retomar o sinterizar la información recolectada a lo largo de los años (CDHFBC, 2007a, 2012), siendo parte de un trabajo metódico que también contribuye a mantener la memoria de desaparecidos, torturados y asesinados. Entre 1995 y 2001 se documentaron 38 casos de desapariciones forzadas y 86 ejecuciones cometidas por el grupo paramilitar Paz y Justicia, que operó en complicidad con el Ejército, y se consideraron nueve de ellos para denunciar la responsabilidad del Estado mexicano ante la CIDH (CDHFBC, 2012, p. 106-107). Un reporte especial de 2010 indica que la documentación de la estrategia militar de contrainsurgencia a lo largo de 21 años evidenció que su objetivo era y seguía siendo garantizar "la explotación extensiva de los recursos naturales que se encuentran dentro del territorio de los pueblos indígenas" (CDHFBC, 2010b, p. 4).

Los informes del Frayba constituyen un archivo que aspira a mostrar la existencia de una historia ininterrumpida de violencia y opresión en Chiapas. Pero también certifican los cambios que se han producido a lo largo de la historia. Uno de ellos atañe a las transformaciones que experimentan las estrategias de contrainsurgencia y los modos de organización de los paramilitares. En efecto, en un informe del año 2008 se afirma que, a diferencia de otras épocas, estos grupos visten de civil con mayor frecuencia, se coordinan de manera más sólida con agentes de los gobiernos estatal y federal y administran recursos económicos que provienen de proyectos del Estado (CDHFBC, 2008b, p. 61).

\section{Prácticas de registro, recopilación y archivación en el Frayba}

El interés del Frayba en la memoria tuvo un precedente y un desarrollo paralelo en las actividades políticoreligiosas de la diócesis de San Cristóbal de Las Casas desde finales de los años sesenta. De alguna manera, estos precedentes legaron ciertos contenidos que pasaron a formar parte del marco interpretativo desde el cual el centro llevó adelante su emprendimiento de memoria y su trabajo de archivo.

Nuestros informantes recordaban a Samuel Ruiz como un especialista en Biblia, entendida como recuperación de la memoria del pueblo. Cuando se produjo el encuentro con el mundo indígena, comenzó el proceso de ligar la memoria antigua del pueblo maya con la memoria del pueblo cristiano para construir una "memoria actual" (informante 3). Aunque hay una cierta cantidad de textos escritos, la acción pastoral de Ruiz fue fundamentalmente oral. Su "profecía" (informante 3) radicaba en el vínculo entre la palabra y la realidad; la palabra se construye desde la realidad: cómo interpela la historia y la realidad a la palabra, no al revés. Dicho de otra manera, la palabra no está contenida en el texto y desde allí desciende, ilumina o se aplica a la realidad, es ella misma iluminada por la realidad. Se enfatiza que 
ha sido importante para la Iglesia católica la memoria de los santos como memoria viva, es decir, una memoria de cómo el cristianismo ha vivido la palabra de Jesús en una actualización constante, una manera de mantener la memoria viva de Jesús como memoria que se hace presente ("todo un caminar", informante 3; "la memoria es importante para seguir el caminar", informante 4).

Ruiz le asignó a la evangelización la urgencia de constituir "la Iglesia autóctona, que ha surgido a partir de sus procesos históricos, sociales, culturales, religiosos y de fe [...]. En ningún momento se ha pretendido quedar, ante las situaciones, [...] en un reduccionismo espiritualista (evasivo de la historia)" (Ruiz, 1993, p. 24). Lo primero que se detectaba era que, al recuperar su memoria, los pueblos se potenciaban, dejaban de ser sujetos dependientes de un patrón. Sin esta memoria no se habría dado el proceso político de Chiapas. Los informantes recuerdan a Ruiz como un "hombre de memoria", pero con un sentido histórico, es decir, atento a "lo que viene"; en lo que ocurre, también en los fracasos, había una apertura al porvenir: "Nada de eso se pierde, hay vida allí reservada, un don reservado. Puede haber fracasos, pero no se pierde" (informante 3). A lo largo del trabajo diocesano, resultó importante el problema de la tradición: los dos mil años de tradición en el cristianismo "implica[ban] alimentarse del pasado para enfrentar el presente y el futuro" (informante 3). En general, la diócesis se alimentó de la memoria de Bartolomé de las Casas (el punto de inflexión fue el año 1974 durante el congreso organizado en esa fecha para conmemorar a la figura de Las Casas). Al llegar a San Cristóbal de Las Casas, Ruiz se encuentra con lo que antes era para él desconocido: "el indio que muere antes de tiempo".

La memoria, finalmente, estaba asociada a otros tres aspectos: 1) la revitalización de la ritualidad, "sin memoria, el rito se vuelve algo muerto, religión seca" (informante 3); 2) el derecho de los pueblos a "ser sujetos de su propia historia", que exigía un modelo político, social y económico distinto al neoliberalismo (Ruiz, 1993, p. 33; 2011, p. 5); 3) el cuidado de las fuentes como manifestación del cuidado de la memoria, por ejemplo, el resguardo del Fondo Samuel Ruiz en el Archivo Diocesano de San Cristóbal de Las Casas o el archivo de Servicios y Asesoría para la Paz (SERAPAZ) sobre las negociaciones entre el EZLN y el gobierno nacional. Estos aspectos, conectados con la tradición de la teología de la liberación latinoamericana, muestran algunos elementos que el trabajo diocesano legó al marco interpretativo con el que el Frayba llevó a cabo sus actividades en cuanto a la memoria y el archivo.

El trabajo de documentación de la actividad diocesana no fue sistemático. En el Archivo Diocesano, sin embargo, se pueden encontrar las actas de las Asambleas Eclesiales ordinarias (anuales) y extraordinarias (en momentos críticos) desde 1975 hasta 2016. Estas asambleas recogen, a juicio de nuestros informantes, la historia política a lo largo de todo este periodo. Mientras la memoria estuvo viva en la acción pastoral del propio Ruiz, "no teníamos que ir al documento" (informante 3), pero en el archivo permanecen las huellas de un proceso que el tiempo va alejando del presente. Otro documento histórico relevante es el Documento del Sínodo Diocesano de 1999, órgano que legisló el "carisma" de Ruiz e institucionalizó la acción pastoral de la diócesis; en él se concentra la memoria del "camino" recorrido. Es una aplicación in situ del derecho canónico. Su modo de construcción, mediante amplias consultas (cuatro años) y participación popular, aseguró que él recogiera una memoria no solo individual sino también colectiva.

Según algunos activistas, en la actualidad la memoria está más presente que antes. Sigue siendo un elemento fundamental de las luchas históricas y de las actuales, por ejemplo, de la Sociedad Civil Las Abejas, que mantienen la memoria de la masacre de Acteal y denuncian la impunidad a través de los comunicados que difunden el 22 de cada mes (CDHFBC, 2011, p. 74; 2014, p. 98). En general, la memoria es usada en "la educación zapatista y en la socialización comunitaria para explicar la [...] resistencia de 
los pueblos rebeldes" (Rico, 2016, p. 24). ${ }^{8}$ La importancia de la memoria proviene de la necesidad de encontrar un sentido a las prácticas y a la tradición oral (dada la "desalfabetización" del pueblo maya). Hubo una memoria conservada oralmente; un informante nos comentó que a menudo durante el trabajo pastoral se decía: "guarden la palabra de los viejitos" (informante 3).

En el marco del legado de la acción pastoral de Ruiz en el emprendimiento de memoria de los activistas del Frayba, así como dentro de su propia trayectoria como organización no gubernamental, se pueden analizar las prácticas de registro, recopilación y archivación llevadas a cabo por el centro.

Los documentos que produce el Frayba circulan en la red y muchos de ellos —como los boletines y los comunicados - se envían expresamente a la prensa estatal, nacional e internacional "por su alto grado de confiabilidad" (CDHFBC, 2008b, p. 146). El proyecto de memoria se consuma en el deseo de que la información registrada y recopilada en el archivo alcance al espacio público y, de esta manera, sea consultada y conocida por la mayor cantidad de personas posibles. En el reporte La legalidad de la injusticia (CDHFBC, 1998c), por ejemplo, se indica que la documentación no se entiende como:

[...] un compendio de datos y cifras de la arbitrariedad, el abuso y la ignominia de las autoridades. No $[\ldots]$ quiere ser un informe más, muerto en un archivo perdido [...] quiere ser un instrumento de reflexión y un estímulo para construir un dique que contenga la violencia institucional contra los ciudadanos y ciudadanas (CDHFBC, 1998, p. 3).

El archivo está, en este sentido, en función del proyecto político del Frayba.

Los activistas del Frayba rechazan la recopilación y el registro repetitivo porque consideran que esta práctica los puede terminar aislando de la comunidad: "No nos interesa documentar por documentar, o ganar casos jurídicos para hacer precedentes" (informante 2). Evitan esa situación en la que el acopio y el registro mecanizados lesionan la intención suprema de la institución archivística que es la de conservar - selectivamente - la información para que pueda ser consultada. El archivo es, en palabras de Jelin (2002), un vehículo de la memoria, un medio para la lucha por la verdad y la justicia. Cuando la documentación es tratada como un fin en sí misma ("documentar por documentar"), el archivo corre el riesgo de convertirse en una entidad autorreferencial que pierde contacto con la sociedad. Se pueden anular los interrogantes acerca de la finalidad para la que fue creado y el archivo puede transformarse en una institución abstracta de producción y acumulación de documentos (Hartog, 2007, p. 130). No obstante, la mera permanencia de los documentos, al tener un carácter social y al mismo tiempo ser relativamente independiente de los usos que se hagan de ellos, los mantiene abiertos a usos futuros, como ha ocurrido en archivos latinoamericanos que contenían información sobre la represión y el terrorismo de Estado. En efecto, una vez que los perpetradores han abandonado el poder, los archivos que contenían las huellas de sus crímenes en ocasiones se han convertido en herramientas para la lucha por los derechos y la memoria de las víctimas. Dos de los casos más conocidos son los "archivos del terror" de Paraguay y el Archivo de la Policía Nacional de Guatemala.

La historia de las luchas a favor de los derechos humanos en Chiapas se muestra en el uso que hace el Frayba de documentos resguardados en su archivo. El archivo es un insumo fundamental para elaborar los

${ }^{8}$ Sobre la memoria de los pueblos indígenas, ver especialmente CDHFBC (2016, pp. 121-124). 
informes. Como señalamos arriba, estos informes poseen un interés historiográfico, no solo memorístico, entre los que se destaca, además de los documentos sobre Acteal, el balance del año 2006 que incluye un numeroso acervo fotográfico. En el reporte de 1998, donde se transcriben testimonios de las víctimas de Acteal, se incluyeron fotografías, pero la novedad del balance de 2006 es que contiene imágenes pertenecientes al propio archivo del Frayba. A partir de ese momento, la organización de los informes seguirá la pauta de combinar crónicas, datos, información sistematizada y documentos fotográficos. Las fotografías del balance de 2006 presentan públicamente a personas cuyos derechos fueron vulnerados y actos de resistencia de las víctimas de esos atropellos. En el primer grupo de imágenes se encuentran activistas detenidos arbitrariamente (CDHFBC, 2007c, pp. 59, 66) e indígenas tsotsiles que fueron torturados (Mauricio Pérez Méndez, Francisco Gómez Méndez, Juan Pérez Pérez, Teodoro Pérez Pérez, Vicente y Mariano López Rodríguez). Se menciona la detención y la tortura de Arturo Hernández Hernández, pero de él no hay documento fotográfico. En el segundo grupo se incluyen varias imágenes de manifestaciones de campesinos que se oponían a los subsidios aplicados al campo, el resguardo de tierras recuperadas por indígenas zapatistas en el municipio de Tumbalá, reuniones estatales y nacionales de organizaciones indígenas y campesinas de defensa de la tierra y de los derechos ejidales de Chiapas, Oaxaca y Michoacán, un acto que conmemoraba los nueve años (en ese entonces) de impunidad por la masacre de Acteal, talleres de promoción y defensa de los derechos humanos en distintas regiones de Chiapas, encuentros de poblaciones desplazadas y, por último, una reunión para tratar el asunto de los desplazamientos internos celebrada entre activistas del Frayba y representantes de la Organización de las Naciones Unidas (ONU) (CDHFBC, 2007c).

El archivo es usado por los activistas del Frayba también con fines de investigación. Estos consultan documentos de otros archivos para elaborar sus informes o confirmar el testimonio de las víctimas que asesoran y acompañan. Se puede citar el caso de los documentos desclasificados por la Agencia de Inteligencia de la Defensa (DIA) de Estados Unidos, difundidos por la investigadora Kate Doyle el 20 de agosto de 2009, que fueron revisados por los activistas del Frayba. Luego de estudiar esos documentos, concluyeron que:

[...] contradicen la versión difundida por la PGR [Procuraduría General de la República] en el Libro Blanco sobre Acteal $^{9}[. .$.$] . En los Archivos improcedentes { }^{10}$ se confirma que la masacre se produjo con el involucramiento y bajo la responsabilidad del Estado, y que el conflicto no se debió a problemas intercomunitarios. Estos documentos confirman lo que repetidamente han afirmado Las Abejas y los sobrevivientes a la masacre (CDHFBC, 2010c, p. 98).

En este proceso de investigación se utilizan fuentes de archivos desclasificados y otros estudios documentados para reforzar el trabajo de documentación y análisis que el Frayba realizó en su momento sobre el caso Acteal. Asimismo, siempre que los activistas reciben nueva información sobre un determinado caso de violación a los derechos humanos, se coteja con los documentos que están en su archivo (CDHFBC, 2004b, p. 3).

\footnotetext{
${ }^{9}$ El "Libro Blanco sobre Acteal" fue la investigación que dio a conocer la PGR en 1998 sobre esta masacre. Las organizaciones de derechos humanos lo consideran la "versión oficial" de los acontecimientos.

10 “Archivos improcedentes" es el título del artículo de Doyle sobre los documentos desclasificados de la DIA que describen el apoyo que brindó el Ejército a los grupos paramilitares que participaron en la Masacre de Acteal.
} 
Los activistas del Frayba manifiestan un deseo de apertura de su archivo físico que, hasta ahora, no ha podido llevarse a cabo. La consulta de los documentos se encuentra vedada incluso para los investigadores: "Para nosotros el archivo del Frayba debería estar abierto, el problema es que se necesita una metodología, y dadas las circunstancias en las que estamos trabajando [...] no podemos tener más personal para que se pueda dedicar a eso" (informante 2). Este archivo cumple un papel crucial en la compilación de pruebas para asistir a las víctimas de los crímenes de lesa humanidad, pero no difiere de otros archivos de organizaciones populares de derechos humanos que afrontan severas restricciones presupuestarias para organizar, describir y conservar sus colecciones documentales. El Frayba no cuenta con personal formado profesionalmente en archivística y de conservación documental. A este respecto, uno de los mayores problemas que afronta el centro es la falta de recursos para estabilizar y organizar los documentos del archivo, con las consiguientes trabas a la consulta que ello genera. En este sentido, el archivo de esta asociación tampoco escapa a una característica compartida por otros archivos de derechos humanos construidos por organizaciones no gubernamentales, que enfrentan constantemente el riesgo de destrucción intencionada, las restricciones a su acceso y la ausencia de archivistas y profesionales de la conservación (Alberch, 2008, p. 43).

El Frayba aspira a abrir en el futuro su archivo "para que esté accesible para todos" (informante 1), pero enfrenta otra dificultad que impide la realización de este proyecto: los documentos contienen información sensible y acceder a ella puede poner en peligro la vida de quienes los consultan (informante 2). Esta advertencia recuerda la máxima benjaminiana según la cual el recuerdo del pasado de los oprimidos se produce siempre en "el instante de un peligro" (Benjamin, 2008, p. 307). Se vuelve necesario mejorar las medidas de seguridad para que el público pueda "acceder a la versión de lo que nosotros hemos documentado" (informante 2). En este sentido, la apertura del archivo del Frayba, que contribuiría al posicionamiento público de su versión sobre la historia de la violencia en Chiapas, está en tensión con la seguridad, sobre todo en un contexto en el que la violencia permanece.

\section{Conclusiones}

En las actividades del Frayba en cuanto a la memoria y el archivo, detectamos al menos dos aspectos. Por un lado, un amplio trabajo de documentación asociado al resguardo o cuidado de los documentos y el análisis de estos. Pero también, por otro lado, un proyecto o emprendimiento político que se alimenta del archivo físico y muestra que los documentos, por sí mismos y aunque permanezcan abiertos a usos futuros, están mermados si no van acompañados —en palabras de un informante- de una "memoria viva", la cual proviene, principalmente, del relato de los testigos, de su inserción polémica en el espacio público, y de la denuncia y judicialización de los casos llevada a cabo por los activistas y las víctimas.

Paralelamente, encontramos dos sentidos de las huellas. En primer lugar, el más evidente: las huellas en su sentido material y que son resguardadas en el archivo. Sin embargo, en segundo lugar, están las huellas en el sentido de restos que se producen en el "caminar" del centro, las cuales se espera que posteriormente sean recuperadas.

La relación del Frayba con el pasado —incluso, en algunos aspectos, la historia de la diócesis de San Cristóbal bajo el obispado de Ruiz - ilustra este segundo sentido de las huellas. La intervención en el ámbito público que caracteriza el activismo de derechos humanos genera múltiples huellas que solo 
posteriormente, en un momento no precisable del futuro, podrán ser recogidas. De allí que se acumulen o amontonen, sin un proceso sistemático de organización, descripción, conservación, curaduría o difusión. Además de las limitaciones de recursos, el día a día de la acción política, el propio activismo, absorbe casi todos los impulsos, lo que deja poco tiempo para los trabajos de archivo. El Frayba reconoce como una de sus tareas esenciales la memoria; desde los marcos que dan sentido a sus actividades, el cuidado de los archivos constituye una herramienta fundamental de su lucha política. Pero su vocación como organización de derechos humanos, en un contexto en el que la violencia no se ha detenido, ha postergado su transformación en un archivo abierto. Como emprendedores de la memoria, valoran el archivo que han construido a lo largo de su trayectoria como un medio irremplazable, pero enfrentan dificultades para mantenerlo, facilitar el acceso público y suscitar otros usos, incluso aquellos que reforzarían su propio proyecto de disputar frente a otros actores, en particular el Estado, la construcción del pasado conflictivo, posicionando públicamente la memoria de las víctimas y la historia de la resistencia indígena en Chiapas.

Una modalidad de lo que Jacques Derrida llamó “mal de archivo", que es constitutivo de todo archivo, en el caso del Frayba radica en la dificultad para desplegar otras posibilidades contenidas en el archivo. Se trata de una situación, hasta ahora inevitable, que está en tensión con el proyecto político de los activistas de reforzar la memoria de las violaciones a los derechos humanos y la demanda de verdad y justicia de las víctimas.

\section{Referencias}

Alberch Fugueras, R. (2008). Archivos y derechos humanos. Trea.

Benjamin, W. (2001). Para una crítica de la violencia y otros ensayos. Iluminaciones IV. Taurus.

Benjamin, W. (2008). Obras. Libro 1, volumen 2. Abada.

Déotte, L.-L. (1998). Catástrofe y olvido. Las ruinas, Europa, el Museo. Cuarto Propio.

Forster, R. (2012). Benjamin. Una introducción. Quadratta; Biblioteca Nacional.

Ginzburg, C. (2010). El hilo y las huellas. Lo verdadero, lo falso, lo ficticio. Fondo de Cultura Económica.

Hartog, F. (2007). Archivos e historia (1979-2001). Historia y Grafía, 28, 127-142.

Jelin, E. (2002). Los trabajos de la memoria. Siglo XXI Editores.

Jiménez Ramírez, M. P. (2000). El rostro de los derechos humanos en Chiapas. El Cotidiano, 16(100), 52-57.

LaCapra, D. (2008). Historia y memoria después de Auschwitz. Prometeo Libros.

Laub, D. (1992). Bearing Witness, or The Vicissitudes of Listening. En S. Felman y D. Laub, Testimony. Crises of Witnessing in Literature, Psychoanalysis, and History (pp. 57-74). Routledge,.

Leyva Solano, X. y Köhler, A. (2016). Las guerras, la otra política y los medios indígenas en movimiento. En M. C. García Aguilar, J. Solís Cruz y P. Uc (coords.), Democracias posibles: crisis y resignificación. Sur de México y Centroamérica (pp. 313-339). Universidad de Ciencias y Artes de Chiapas.

López Pacheco, J. A. (2015). El campo de las ONG de derechos humanos en México: recursos y agendas. El Cotidiano, 194, 97-106.

López Pacheco, J. A. (2017). ONG de derechos humanos y violencia en México. Institucionalización, fragmentación y dinámicas contenciosas. En A. Estévez y D. Vázquez (coords.), 9 razones para (des) confiar de las luchas por los derechos humanos. Universidad Nacional Autónoma de México; Facultad Latinoamericana de Ciencias Sociales, Sede Académica de México.

López Pacheco, J. A. y Hincapié Jiménez, S. (2016). Ciclos de movilización y crisis de derechos humanos. La acción colectiva de las ONG nacionales y los derechos humanos en México. Revista de Estudios Sociales, 56, 26-38.

López Pacheco, J. A. y Hincapié Jiménez, S. (2017). Derechos humanos y activismo legal transnacional. Estrategias de las ONG en México y Colombia. Perfiles Latinoamericanos, 25(49), 7-34.

Maza Calviño, E. C. (2012). Derechos humanos. México: de retórica sin compromiso. Facultad Latinoamericana de Ciencias Sociales, Sede Académica México. 
Rico Montoya, A. (2016). Narrativas de violencia y resistencia de las infancias zapatistas. Educación autónoma y contrainsurgencia en Chiapas. Argumentos, 29(81), 13-35.

Ruiz García, S. (1993). En esta hora de gracia. Carta pastoral con motivo del saludo de S.S. el Papa Juan Pablo II a los indígenas del continente. Ediciones Dabar.

Ruiz García, S. (2011). Una nueva hora de gracia. Carta pastoral. Ediciones Mujeres y Hombres de Buena Palabra. https://komanilel.org/BIBLIOTECA_VIRTUAL/Una_nueva_hora_de_gracia.pdf

Traverso, E. (2007). El pasado, instrucciones de uso. Historia, memoria, política. Marcial Pons; Ediciones Jurídicas y Sociales.

Informes consultados

Centro de Derechos Humanos Fray Bartolomé de las Casas (1995). Zona Norte. "El otro cerco". CDHFBC.

Centro de Derechos Humanos Fray Bartolomé de las Casas (1998a). Acteal: entre el duelo y la lucha. CDHFBC.

Centro de Derechos Humanos Fray Bartolomé de las Casas (1998b). ...ésta es nuestra palabra. Testimonios de Acteal. CDHFBC.

Centro de Derechos Humanos Fray Bartolomé de las Casas (1998c). La legalidad de la injusticia. CDHFBC.

Centro de Derechos Humanos Fray Bartolomé de las Casas (2001). Donde muere el agua. Expulsiones y derechos humanos en San Juan Chamula. CDHFBC.

Centro de Derechos Humanos Fray Bartolomé de las Casas (2004a). La dilación de la justicia y el caso Acteal. CDHFBC.

Centro de Derechos Humanos Fray Bartolomé de las Casas (2004b). La paramilitarización en la Zona Norte de Chiapas. CDHFBC.

Centro de Derechos Humanos Fray Bartolomé de las Casas (2005). Balance anual 2005 sobre la situación de los derechos humanos en Chiapas. CDHFBC.

Centro de Derechos Humanos Fray Bartolomé de las Casas (2007a). Acteal a 10 años. Recordar para no olvidar, hasta que la justicia se siente entre nosotros y nosotras. CDHFBC.

Centro de Derechos Humanos Fray Bartolomé de las Casas (2007b). Acteal, ante la justicia. Breve reporte jurídico a 10 años de la Masacre de Acteal. CDHFBC.

Centro de Derechos Humanos Fray Bartolomé de las Casas (2007c). Balance anual 2006 sobre la situación de los derechos humanos en Chiapas. CDHFBC.

Centro de Derechos Humanos Fray Bartolomé de las Casas (2008a). Acteal ante la Suprema Corte de Justicia de la Nación. La defensa de los paramilitares. CDHFBC.

Centro de Derechos Humanos Fray Bartolomé de las Casas (2008b). Balance anual 2007 sobre la situación de los derechos humanos en Chiapas. CDHFBC.

Centro de Derechos Humanos Fray Bartolomé de las Casas (2009a). Balance anual 2008 sobre la situación de los derechos humanos en Chiapas. CDHFBC.

Centro de Derechos Humanos Fray Bartolomé de las Casas (2009b). Por la verdad y la justicia. Acteal, 11 años, 5 meses y 17 días de impunidad. ¿Cuântos más? CDHFBC.

Centro de Derechos Humanos Fray Bartolomé de las Casas (2010a). Agresiones, desalojo forzoso y tortura a manifestantes en el municipio de Las Rosas, Chiapas, con la complicidad de autoridades estatales y municipales. CDHFBC.

Centro de Derechos Humanos Fray Bartolomé de las Casas (2010b). Agresiones y tortura en Mitzitón. CDHFBC.

Centro de Derechos Humanos Fray Bartolomé de las Casas (2010c). Balance anual 2009 sobre la situación de los derechos humanos en Chiapas. CDHFBC.

Centro de Derechos Humanos Fray Bartolomé de las Casas (2011). Late la tierra en las veredas de la resistencia. Una mirada a las experiencias de lucha de los pueblos de Chiapas en la defensa de sus derechos. Informe 2010. CDHFBC.

Centro de Derechos Humanos Fray Bartolomé de las Casas (2012). Entre la política sistémica y las alternativas de vida. Informe sobre la situación de los derechos humanos en Chiapas durante los gobiernos federal y estatal 2006-2012. CDHFBC.

Centro de Derechos Humanos Fray Bartolomé de las Casas (2014). Los derechos humanos a debate. Entre el cinismo oficial y la dignidad de los pueblos. Informe 2013. CDHFBC.

Centro de Derechos Humanos Fray Bartolomé de las Casas (2016). Los caminos de la resistencia. Informe Frayba 2016. CDHFBC. 